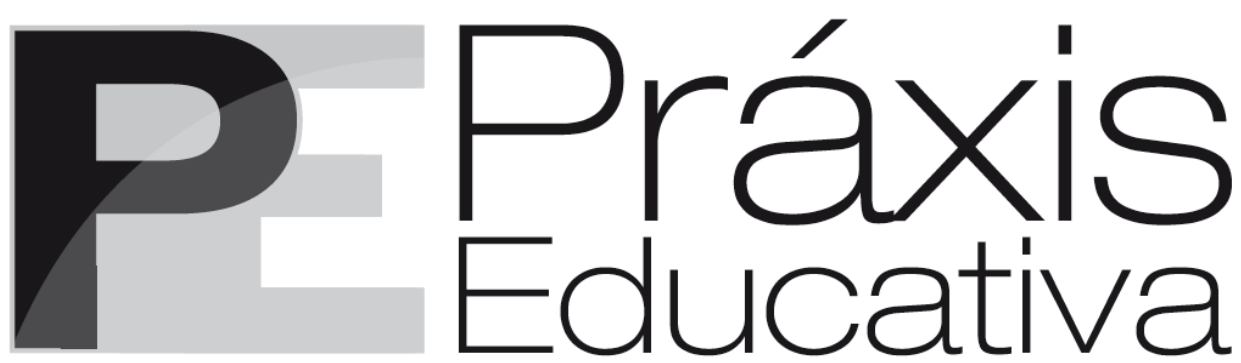

ISSN 1809-4031

elSSN 1809-4309

https://doi.org/10.5212/PraxEduc.v.16.16640.030

\title{
Por uma educação freireana que atue contra a desigualdade de gênero no
} Brasil contemporâneo

\section{A Paulo Freire based education in favor of gender equality in contemporary Brazil}

\section{Por una educación freireana que trabaja contra la desigualdad de género en el Brasil contemporáneo}

\author{
Maria Clara Maciel de Araújo Ribeiro* \\ (iD https://orcid.org/0000-0001-9205-5858 \\ Isabela Maria Oliveira Catrinck ${ }^{* *}$ \\ (D) https://orcid.org/0000-0001-6843-8592 \\ Sandy Aparecida Barbosa Magalhães** \\ iD https: / / orcid.org/0000-0003-3656-8653
}

\begin{abstract}
Resumo: Este estudo discute relações existentes entre uma educação freireana pautada em valores democráticos e o papel de discussões sobre desigualdade de gênero na escola brasileira. Para tanto, indagamo-nos sobre o papel que discussões sobre gênero e diversidade sexual desempenham na escola e na construção de uma sociedade mais justa e equânime, refletindo sobre as consequências de se promover interdições na educação escolar em temas fundamentais ao equilíbrio de forças sociais. Ao final, o estudo considera que a inserção de tal temática na escola contribui para a desconstrução de estereotipias, o fomento ao respeito mútuo e à diminuição de preconceitos, desenvolvendo uma consciência crítica coletiva capaz de levar os estudantes a olharem para si e para o outro como partes integrantes de um mesmo corpo social, orientando as novas gerações para o ideal da igualdade dentro da diversidade.

Palavras-chave: Desigualdade de gênero. Educação democrática. Pedagogia freireana.
\end{abstract}

Abstract: This study discusses the relationship between the democratic values-based Freire's education method and the discussions about gender inequality in Brazilian schools. In this concern, we asked ourselves

\footnotetext{
* Professora da Universidade Estadual de Montes Claros. E-mail: <mclaramaciel@hotmail.com>.

** Mestranda no Programa de Pós-Graduação em Educação da Universidade Estadual de Montes Claros. E-mail: $<$ isabelac.educacao@gmail.com>.

*** Mestranda no Programa de Pós-Graduação em Educação da Universidade Estadual de Montes Claros. E-maill: $<$ sandy.magalhaes91@gmail.com>.
} 
Por uma educação freireana que atue contra a desigualdade de gênero no Brasil contemporâneo

about the role that discussions about gender and sexual diversity play in school and in the construction of a fairer and more equitable society, reflecting on the consequences of promoting interdictions in school education on themes fundamental to the balance of social forces. The study considers that the insertion of such theme at school contributes to the deconstruction of stereotypes, the promotion of mutual respect and the reduction of prejudices, developing a collective critical awareness capable of leading students to look at themselves and at each other as integral parts of the same social body, guiding new generations towards the ideal of equality within diversity.

Keywords: Gender Inequality. Democratic education. Freirean pedagogy.

Resumen: Este estudio discute las correlaciones existentes en la educación de Freire pautada en valores democráticos y en el papel de los debates sobre la desigualdad de género en las escuelas brasileñas. Por eso, nos preguntamos sobre el papel de discusiones de género y diversidad sexual en la escuela y en la construcción de una sociedad más justa y ecuánime, reflexionando sobre las consecuencias de promover interdicciones en la educación escolar en temas fundamentales para el equilibrio de fuerzas sociales. Al final, el estudio considera que la inserción de esta temática en la escuela contribuye a la deconstrucción de estereotipos, la promoción del respeto mútuo y la reducción de prejuicios, desarrollando una conciencia crítica colectiva capaz de tomar a los estudiantes a mirarse a sí mismos y a los demás como parte integrante del mismo cuerpo social, orientando/dirigiendo las nuevas generaciones hacia el ideal de igualdad en la diversidad.

Palabras claves: Desigualdade de género. Educación democrática. Pedagogia de Freire.

\section{Considerações iniciais}

Em regimes democráticos, a participação ativa e livre dos indivíduos em temas que circulam na esfera de discussão pública é um dos princípios fundamentais de uma educação transformadora. Não se prepara o sujeito para a vivência democrática e cidadã excluindo-o da reflexão crítica de temáticas caras a seu tempo. A partir disso, buscamos compreender, por meio de premissas de uma educação freireana pautada em valores democráticos, quais são as contribuições que as discussões sobre gênero oportunizam à escola brasileira.

Para tanto, indagamo-nos sobre o papel que discussões sobre gênero e diversidade sexual desempenham na escola e na construção de uma sociedade mais justa e equânime, refletindo sobre as consequências de se promover interdições na educação escolar em temas fundamentais ao equilíbrio de forças sociais Diante disso, este artigo realiza um estudo qualitativo que pensa na contribuição da pedagogia de Paulo Freire $(1981,1996,2000)$ para a compreensão do papel da escola no enfrentamento da desigualdade de gênero no Brasil, focalizando a pedagogia freireana como um recurso catalizador da igualdade e da liberdade que pode se atingir quando a educação é emancipadora.

Embora discussões sobre gênero e diversidade sexual estejam na pauta de debates públicos, distintas interdições as excluem da escola, sob a alegação de preservação de "valores da família", num artificioso argumento que polariza gênero e diversidade sexual à categoria família. Neste estudo, tais interdições são caracterizadas como atributos da escalada neofascista em voga no Brasil atual. Para compreender que tipo de educação se rejeita neste cenário e que tipo de educação se almeja para superar a tendência antidemocrática, partimos do legado de Paulo Freire (1981, 1996, 2000) para a constituição do que se pode chamar de pensamento educacional brasileiro.

Durante a sua vida, Freire atuou como militante, pesquisador e educador a favor dos interesses das classes sociais oprimidas. Sua busca pela união entre teoria e práxis pautava-se no entendimento de que, a partir de uma sociedade humanizada e igualitária, a democracia poderia se efetivar. Os seus estudos são reconhecidos e respeitados mundialmente, sendo considerado um dos maiores intelectuais no que tange aos estudos sobre educação e sociedade. Suas asserções 
políticas e filosóficas são, ainda hoje, palco para as lutas em defesa da democracia e de uma educação libertadora. Apesar disso, tendo em vista as relações entre escola, sociedade e sistema econômico, décadas após a sua morte, deparamo-nos hoje com setores da sociedade brasileira que temem o sopro de esperança de novos tempos prenunciada pela obra de Freire. É justamente neste lugar que nos posicionamos para pensar questões de gênero no Brasil contemporâneo.

É fato que a educação formal brasileira é reflexo da sociedade que fomos constituindo (e nos constituindo) ao longo de nossa história: uma sociedade escravocrata e colonial, forjada por ideais burgueses e individualistas, cujas práticas políticas nunca priorizaram as massas mazeladas pelo capital, mas as segregaram e aprisionaram sob o rótulo de "minorias" a serem dominadas pelo poder hegemônico. Nessa conjuntura, o currículo escolar tornou-se cenário de perpetuação de interesses do Estado, logo, não houve - e ainda não há - espaço efetivo para uma educação universal e emancipadora, voltada para a formação de sujeitos críticos e conscientes de seu papel e direito enquanto cidadãos. Nesse âmbito, destacam-se a necessidade de estudos de gênero e do debate acerca da diversidade sexual no ambiente escolar como um dos componentes de uma educação crítica contra a qual atuam hoje formas sociais conservadoras. Na visão de Silva (2021, p. 5), "o diálogo é o balizador de uma educação que se pretende libertadora, enquanto o antidiálogo transforma as relações humanas em práticas autoritárias e aprisionadoras" que exercem força centrípeta sobre o discurso. Nessa perspectiva, as interdições sobre a temática gênero na escola brasileira, como prática autoritária de antidiálogo, visa perpetuar modos de relação que desequilibram forças sociais ao tentar reprimir e silenciar modos de ser e de existir.

Ao traçar a trajetória de políticas públicas educacionais que abarcam discussões sobre gênero e/ou sexualidade no Brasil, torna-se perceptível que a cada passo para frente, dois são dados para trás, num evidente esforço de certos grupos políticos para manter sob controle o conhecimento circulante na escola, freando avanços capazes de orientar uma escalada democrática na escola e na sociedade brasileira, o que (des)equilibraria correlações de forças sociais preexistentes. A exemplo, destacamos hoje a atuação do movimento autointitulado Escola sem Partido, bem como os projetos de lei por ele elaborados e difundidos, que apregoam, entre outras coisas, a falácia da "ideologia de gênero", defendendo que professores devem ser cerceados em sua atuação perante o risco de "desvirtuarem" estudantes com "valores da esquerda".

No tocante à sexualidade, este movimento prega o combate à chamada "doutrinação ideológica de esquerda" nas escolas, com intento de se resgatar uma concepção essencialista que defende a ideia de que gênero e sexualidade são dados naturais, associais e transhistóricos, produzindo um "terrorismo moral" que posiciona quem pensa diferente como deturpadores da moral e dos bons costumes. Nesse sentido, várias investidas deste movimento (incluindo projetos de lei), visando o silenciamento da escola no que se refere às questões de diversidade e igualdade de gênero, ocorreram nos últimos anos, num esforço para se apagar essas temáticas do currículo escolar, produzindo alianças com setores conservadores do Estado, como parte do Congresso Nacional e de grupos católicos e neopentecostais.

Entendemos que movimentos que produzem interdições e silenciamentos na escola, cobrindo com o manto negro do tabu temáticas socialmente circulantes e que são objeto de fala e vivência dos próprios estudantes, produzem uma contraforça à educação democrática vislumbrada por Paulo Freire. De nosso ponto de vista, uma educação e sociedade democráticas só são assim, de fato, se atenderem a todos os sujeitos, propiciando-os condições para viver em harmonia consigo e com o outro. Isso envolve a compreensão da educação como ato político e social, o que ultrapassa o limiar do conhecimento enquanto técnica e o posiciona como substrato de uma formação emancipatória. 
É diante desse contexto que nos propomos neste artigo a compreender, numa perspectiva freireana, a contribuição da inserção da temática gênero na escola frente à construção de uma sociedade mais justa e equânime. Para tanto, inicialmente resgatamos pontos representativos da obra de Freire (1981, 1996, 2000) para, em seguida, tomá-los como premissa da discussão sobre gênero na esfera educacional. Por fim, apresentamos as considerações finais do estudo, na esperança de demonstrar que temos base teórica e vivencial para progredir.

\section{Para além da leitura da palavra: por uma leitura de mundo crítica e consciente}

Nos últimos tempos, uma série de acontecimentos no cenário político brasileiro evidenciaram que as bases de nossa recente democracia são menos sólidas do que se imaginava. Por outro lado, inquietações acerca da falta de espírito democrático da sociedade brasileira já incomodavam a Paulo Freire. Se outrora demos sinais de avanços democráticos e o delineamento de alicerces de um pensamento educacional brasileiro, ainda que no âmbito técnico-pedagógico, visando maior organização escolar ${ }^{1}$, a fragilidade da democracia evidenciava-se tanto no golpe que ocorrera em 1930 quanto nas relações sociais, e a posteriori no golpe de 1964. Paulo Freire (2010) afirma que a inexperiência democrática possui raízes culturais na sociedade brasileira, dificultando, assim, a consolidação de nossa democratização. Parece-nos que a imposição herdada desde os tempos de colônia perpassou o período republicano e se estendera no século seguinte, refletindo ainda hoje na sociedade brasileira.

A pedagogia de Paulo Freire desenvolve-se, então, nesse cenário, visando a superação de tais heranças culturais, de modo a proporcionar uma autonomia cultural ao homem na sociedade. Para Franco (2017, p. 157), a pedagogia de Freire "surge como um rompimento epistemológico e político frente ao que se desenhava como perspectiva política na educação e, mais que tudo, surge como uma resistência à lógica liberal e tecnicista que marcava a história política do Brasil até aquele momento", reforçando os ideais de democracia e universalização do ensino.

Sob essa ótica, Fonseca (2011, p. 107) afirma que "Paulo Freire entende a democracia como uma forma de aprendizado, em que o homem vai refletindo sobre sua posição e, consequentemente, isso o motiva a mudar o mundo em que vive". Sendo assim, a conscientização permite que o homem compreenda a estrutura social e consiga enxergar as classes dominantes e violentas democraticamente. Vale destacar a importância da compreensão do tema consciência na obra de Freire, tendo em vista que a conscientização constitui o bojo de sua pedagogia. Freire (2014, p. 860) evidencia a consciência intransitiva no homem como "limitação de sua esfera de apreensão"; e só à medida que ele amplia a sua capacidade de "dialogação" e envolvimento com as questões que o cercam é que ele é capaz de se transitar, alcançando uma consciência transitiva. Contudo, essa consciência transitiva é, a priori, ingênua, frágil na argumentação, muito emocional, sem prática do diálogo e pautada por respostas mágicas que, segundo o autor, podem levar a uma consciência fanatizada. Afinal, o que vinha se sentindo na sociedade, naquele tempo, segundo Freire (2014, p. 625), era a presença de um homem "convertido em espectador, dirigido pelo poder dos mitos que forças sociais poderosas criam para ele. Mitos que, voltando-se contra ele, o destroem e aniquilam" - situação que guarda muitas semelhanças com o Brasil atual.

A mudança da consciência intransitiva para a consciência transitiva ingênua se dá como consequência das próprias transformações econômicas da sociedade. Não obstante, alcançar a consciência transitiva crítica só é possível por meio da educação; uma educação dialogal que considere

\footnotetext{
${ }^{1}$ Referimo-nos aos ideais de Anísio Teixeira, que já traçava as bases do pensamento educacional brasileiro, pautados na democracia desde a organização escolar até a sala de aula; sendo ele signatário do Manifesto dos Pioneiros da Educação Nova (1932).
} 
a responsabilidade social e política do homem de modo a compreender criticamente problema sociais, representando a matriz da democracia. Nesse sentido, Paulo Freire desenvolve sua pedagogia com participação popular e através da realidade do próprio aluno, em ambientes tidos como não-escolares, justamente no intuito de favorecer o desenvolvimento de tal consciência a pessoas e lugares determinados.

Desde o início de sua trajetória como educador, no setor de educação do Serviço Social da Indústria - SESI, Paulo Freire pôde desenvolver os chamados Círculos de Pais e Professores; encontro nos quais a direção ouvia atentamente o relato dos pais de modo a adequar suas práticas às necessidades deles. Os círculos proporcionavam um ambiente de acolhimento no qual os trabalhadores podiam manifestar suas dúvidas e inquietações; os pais orientavam as ações, que eram passíveis de serem modificadas e repensadas quando necessário, objetivando a integração da realidade desses sujeitos ao cotidiano educacional. As decisões não deveriam, então, serem tomadas unilateralmente por uma gestão, mas em conjunto com os aprendizes, considerando seus anseios e vivências, num anúncio de uma educação libertadora para além da esfera escolar. A conscientização da população poderia ocorrer, portanto, em espaços diversos - praças, periferias, igrejas, repartições públicas - mas em consonância com a pluralidade de ideias a partir de princípios democráticos.

Ao longo dos anos, cada vez mais, Paulo Freire desenvolvia ações educacionais envolvendo a população, além de começar a se aproximar da universidade, onde se torna professor emérito e, posteriormente, professor titular, defendendo sua tese de doutorado em 1959 e alcançando, assim, mais visibilidade no cenário brasileiro por ecoar o discurso de conscientização das massas e a ampla defesa da democracia. Segundo aponta Haddad (2019), já inserido no Serviço de Extensão Cultural - SEC, da Universidade de Recife, Paulo Freire integra também o Movimento de Cultura Popular - MCP, criado em 1960, que objetivava democratizar a educação e a cultura. As ações do MCP foram se ampliando e o movimento contava com mais de 50 Centros de Cultura Popular em Recife e, com essa expansão, a alfabetização de jovens e adultos torna-se uma demanda importante, fazendo com que algumas cartilhas específicas de leitura fossem criadas. Contudo, Freire não era adepto às cartilhas, pois para ele os alunos deveriam pensar com seus próprios recursos, conforme afirma Haddad (2019), fazendo, assim, com que constantemente os métodos fossem reavaliados, considerando sobretudo a construção dialógica do conhecimento com os alunos. Nesse cenário, Paulo Freire dialogava também com sua esposa, Elza, que era professora primária e alfabetizadora, para possibilitar uma alfabetização que considerasse o aluno e permitisse que ele fosse, de fato, um agente da transformação social a partir do que a educação poderia lhe oferecer. O método desenvolvido por Freire, então, envolve imagem e palavra, de modo que a experiência da vida do aluno seja considerada no processo de aquisição da leitura e da escrita através de temas pertencentes ao seu universo.

Mesmo com o processo de alfabetização elaborado e após realizar alguns testes bemsucedidos, Paulo Freire, junto à Elza, decide que era melhor não definir temas de alfabetização previamente; eles deveriam emergir do próprio grupo de alunos, a partir da realidade deles. Freire desenvolve, dessa forma, um método de alfabetização completamente pensado em prol da população, dando autonomia aos alfabetizandos para que eles sejam sujeitos agentes e não pacientes do processo de alfabetização. O processo de alfabetização propiciaria ao aluno mais do que a leitura de palavras, mas a leitura do mundo, tornando-o um homem-sujeito. Há, na metodologia e, especialmente, na filosofia de Freire, uma motivação democrática genuína, propensa ao diálogo e disponível à cooperação mútua. Conforme afirma Freire (2014, posição 1719), eles não poderiam aceitar uma democratização da cultura e, por conseguinte, o fortalecimento de uma sociedade democrática através de fórmulas feitas pelos educadores que fossem entregues aos homens "como prescrições a serem seguidas". O homem sujeito no mundo, alcançando a

Práxis Educativa, Ponta Grossa, v. 16, e2116640, p. 1-14, 2021

Disponível em: < https://www.revistas2.uepg.br/index.php/praxiseducativa > 
consciência crítica, é capaz de tornar-se de fato crítico e romper com idealismos utópicos e com uma tradição colonial e elitista na qual o poder é exercido sobre o povo e não emanado do povo. A partir de Freire, o pensamento educacional brasileiro vem se desenhando, então, a partir de ideais emancipatórios e que promovam a conscientização do/a cidadão/ã, visando ao fortalecimento da democracia, possibilitando um espaço no qual a educação seja para todos. Para alguns, alcançar tal intento é afrontoso e, para a classe dominante, subversivo; afinal, a ordem já havia sido por ela determinada e as classes irrevogavelmente definidas.

Os anos 1960 já apresentavam conflitos políticos acentuados em todo o território nacional, e foi nesse cenário que Paulo Freire expandia o seu método de alfabetização que associava a conscientização política da população ao processo educacional. Lembremo-nos de que "[n]a América Latina, o golpe de Estado se tornou a resposta das elites econômicas e militares no poder às crises provocadas pela emergência popular" (FREIRE, 2016, p. 120). Assim, ao incentivar a leitura de mundo e não apenas a leitura da palavra, Freire não adere a um processo educacional mecânico, mas reconhece a necessidade do indivíduo enxergar a si mesmo na sociedade e de se apropriar da condição de sujeito para, assim, politizar-se e transformar a sociedade.

Nessa perspectiva, sob a ótica da pedagogia de Paulo Freire, o alcance da democracia pela educação precisa perpassar o aluno e ultrapassar os muros da escola. Isso significa que o aluno precisa participar do ato educativo de modo livre e crítico, pautando-se em ideais democráticos que, vivenciados como uma experiência escolar, poderão ser expandidos para o mundo social, o que aumenta a importância da escola se impor cada vez mais como um lugar orgânico de vivência e fortalecimento da democracia.

De nosso ponto de vista, historicamente, a falta de organicidade de muitas escolas tem estreita relação com o domínio e poderio das elites sobre a educação. Se a Educação Básica, na visão de alguns, serviria apenas como uma etapa antecessora ao Ensino Superior e se, há algumas décadas, não se havia previsão de classes populares chegarem à universidade, qual seria, então, a serventia de se incentivar que jovens e adultos se alfabetizassem e avançassem na escolarização para além do que requer a sua atividade laboral? $\mathrm{Na}$ visão de dados grupos, a formação intelectual parecia ser propriedade da elite e qualquer indicação de movimento nesse status quo corresponderia a um contra-movimento. Ora, não é à toa que transformações sociais ocorrem diluídas no tempo, sem movimentos bruscos e repentinos, mas como sedimentos acumulados de maneira contínua e quase imperceptíveis à superfície.

Portanto, a educação como vinha sendo desenvolvida pelas classes dominantes e por grande parte do governo brasileiro era uma máquina construída para manter e perpetuar o status quo. Por tal motivo, ao alfabetizar mais de 400 iletrados na cidade de Angicos (RN) e permitir que um desses alunos, inclusive, lesse uma carta de própria autoria para o presidente da república no dia do encerramento das aulas, dizendo que "temos muita necessidade das coisas que nós não sabia e que hoje estamos sabendo. Em outra hora, nós era massa, hoje já não somos massa, estamos sendo povo" é uma grande movimentação nas bases sólidas das classes dominantes e uma ameaça a esse status quo que de um modo ou de outro ecoa e perturba ainda hoje o poder hegemônico (FERREIRA, 1963, apud HADDAD, 2019, p. 852).

Como relembra Freire (2016, p. 87), quando um "ex-analfabeto" faz um discurso e afirma não ser mais massa, ser agora "povo", "ele escolheu participar da decisão que só o povo possui e renunciou à resignação emocional das massas, de modo que se politizou”. É possível notar, então, a apropriação da consciência crítica e o rompimento com a consciência ingênua, possibilitando, então, o fortalecimento das bases democráticas, fundamentais para a consolidação do pensamento educacional brasileiro. 
De modo análogo, é possível pensar a discussão sobre gênero no Brasil de nossos tempos: em que medidas o status quo e o poder hegemônico atuam pela manutenção e perpetuação dos estereótipos de gênero, invalidando outras formas de ser e existir? Se a escola se exclui do debate público sobre questões de gênero e de sexualidade, ela permite que apenas uma voz continue a ecoar entre suas paredes: a voz do senso-comum conservador, do mesmo e do preconceito, como discutimos na seção abaixo.

\section{Concepções democráticas do pensamento freiriano: perspectivas de gênero no espaço escolar brasileiro}

Como discutimos, o ideal de escola inclusiva e livre, que atue contra a marginalidade e a favor da equalização social está na base de uma sociedade verdadeiramente democrática. Se almejamos fortalecer as bases de nossa frágil democracia, resta clara a necessidade não apenas de se compreender o papel da escola nesse processo, mas também de subsidiá-la na consecução de seus objetivos. À revelia disso, movimentos político-governamentais atuam hoje para o exato oposto: transformar a escola num lugar de controle, exercendo forças centrípetas sobre discursos tidos como desejáveis e forças centrífugas sobre discursos considerados indesejáveis.

Entre os discursos indesejáveis estão as discussões sobre gênero e sexualidade. Entre as forças centrífugas, está a exercida pela Ministra de Estado da Mulher, da Família e dos Direitos Humanos, Damares Alves, que entre outras manifestações disse que "a escola não pode ensinar nada que atente contra a moral, a religião e a ética da família" 2 . Como há moral, ética, religião e famílias para todos os gostos, o que se busca com um enunciado como este é dizer que a escola está sob vigilância e que ela não pode expandir o universo dos sujeitos, tendo a obrigação de manter cada um confinado nos limites de seu próprio universo.

Se a fala da ministra fosse levada a sério, entre inúmeros outros temas, discussões sobre gênero e sexualidade seriam definitivamente banidas da escola. Educação sexual, estereotipias de gênero e violência contra a mulher seriam (como por vezes são) censurados como "atentados à moral da família". Na contramão dessa visão, está a verdade inconveniente dos números: o Brasil é o $5^{\circ}$ país com mais casos de feminicídio do mundo e demorará cerca de 257 anos para promover igualdade de gênero no trabalho, segundo pesquisa realizada pelo Fórum Econômico Mundial ${ }^{3}$. Isso nos parece razão suficiente para que relações de gênero sejam discutidas com prioridade pela escola, pois embora lutas e conquistas históricas de movimentos feministas em favor da igualdade de gênero tenham ocorrido nas últimas décadas, desigualdades de gênero ainda persistem substancialmente na sociedade brasileira. Essas desigualdades recaem sobre a vida de todos aqueles que não pertencem à figura do homem heterossexual, branco, burguês e em idade produtiva. Tratase de uma narrativa cotidianamente sustentada pelo capital, em estreita simbiose com a ideologia patriarcal que se instala e se diversifica em distintas formas de opressão - sempre estruturadas em pressupostos que hierarquizam gêneros, constituindo-os em uma realidade objetiva que tem por padecentes os alheios ao falocentrismo.

Nessa perspectiva, percebemos o espaço escolar como um palco de disputa de poder utilizado pelos Estados-nação para a manutenção de um sistema patriarcal, tendo em vista que

\footnotetext{
2 Fala pública da ministra em visita a Belo Horizonte em novembro de 2019. Notícia disponível em: https://veja.abril.com.br/educacao/damares-anuncia-canal-para-denunciar-professores-por-atos-contra-a-familia/. Acesso em: 06 mar. 2020.

Reportagem veiculada no G1 em dezembro de 2019. Disponível em: https://g1.globo.com/economia/noticia/2019/12/17/desigualdade-de-genero-no-trabalho-so-acabara-daqui-a-257anos-aponta-forum-economico-mundial.ghtml. Acesso em: 06 mar. 2020.
}

Práxis Educativa, Ponta Grossa, v. 16, e2116640, p. 1-14, 2021

Disponível em: < https://www.revistas2.uepg.br/index.php/praxiseducativa> 
"currículos e programas constituem o instrumento mais poderoso de intervenção do Estado no ensino", o que significa tanto a possibilidade de exclusão e controle de temas capazes de causar (des)equilíbrios nas correlações de forças sociais quanto a inclusão de temas ou perspectivas capazes de manter o estado de coisas (ABUD, 1998, p. 25). Logo, é perceptível a fragilidade do sistema educacional brasileiro para promover igualdades de gênero. Contrariamente, o que percebemos são práticas atuantes no gerenciamento de artifícios sexistas que mantém a escola distante dos preceitos de escola inclusiva e equânime de que falávamos há pouco.

Com vistas no ideal de educação democrática freireana, precisamos compreender quais são os determinantes que conduzem a educação brasileira à objeção da temática gênero e de suas manifestações e implicações. Para tanto, é impensável não considerar as características sóciohistórico-culturais da formação da sociedade brasileira, pois elas refletem diretamente nos moldes contemporâneos da educação formal nacional. Somos herdeiros de uma estrutura escravocrata e colonial, cujos fundamentos patriarcais, latifundiários e exploratórios perduraram irretocáveis por mais de 300 anos e ainda hoje mostram os reflexos de sua influência em nossos dias. Posteriormente, somamos à nossa herança uma controversa República, tomada por um ideal burguês, individualista, de democracia tanto quanto questionável.

Não há dúvidas de que a nossa história repercute fortemente em nosso sistema educacional, que se tornou precário, "inorgânico, desarticulado, retrógrado, ineficiente, injusto e desarticulado", como sustenta Nunes (2019, p. 69), fazendo-se lócus à disposição da ideologia capitalista e patriarcal.

Desde suas origens, o sistema educacional brasileiro foi instituído pelas convenções da Igreja e a posteriori pelas do Estado, sendo permeado por avanços e retrocessos em favor das elites. Veja-se, por exemplo, que por décadas as políticas educacionais destinadas às massas limitaram seus esforços ao oferecimento prioritário do ensino técnico de leitura, escrita e matemática básica, abstraindo abordagens críticas e emancipadoras que possibilitariam a redução de desigualdades sociais. Freire (1996, p. 18) reitera que esse cenário ilustra a "malvadeza neoliberal" que tenta nos convencer de que a realidade social na qual estamos inseridos é natural, por meio da circulação de aforismos pré-construídos que sustentam que "o mundo é assim mesmo" e que o desemprego "é uma fatalidade de nossos tempos". Nessa perspectiva, Gramsci (2005) entende esse contexto como gerador de "subordinação intelectual". Ele faz uso desse conceito para estampar os aparelhos ideológicos da dominação econômica, utilizados pelo Estado, para o controle e subalternidade das classes populares, num esforço para que a cegueira ideológica dos dominados não desvele as ações autoritárias, desrespeitosas e desiguais das sociedades capitalistas.

Num contexto de dominação como o relatado acima, de que modo fica então a educação para a igualdade de gênero? Sabe-se que hoje interdições múltiplas impedem essa temática de circular livremente na escola. Nos últimos vinte anos, contudo, do ponto de vista legal, não podemos negar que a educação brasileira obteve uma provisória e ilusória democracia no que tange aos estudos de gênero e diversidade sexual, principalmente através de regulamentos como o Programa Nacional em Direitos Humanos (BRASIL, 1996), sendo o primeiro documento oficial do Estado a grafar o termo "homossexuais" em seu texto, representando um avanço na visibilidade desses sujeitos; os Parâmetros Curriculares Nacionais (BRASIL, 1996), produzidos a partir da Lei de Diretrizes e Bases da Educação Nacional - LDB de 1996, considerado por muitos autores, ainda hoje, o mais importante avanço em relação à legitimação de uma perspectiva de gênero nas políticas educacionais; a criação do Conselho Nacional de Combate à Discriminação (BRASIL, 2004), cuja função é o acompanhamento de Políticas Públicas direcionadas à defesa dos direitos sociais e individuas de sujeitos alvos de discriminação racial e outras intolerâncias e o Programa Brasil sem Homofobia, de 2004, lançado após várias discussões entre o Estado e a sociedade civil, objetivando promover a

Práxis Educativa, Ponta Grossa, v. 16, e2116640, p. 1-14, 2021

Disponível em: < https://www.revistas2.uepg.br/index.php/praxiseducativa> 
cidadania e os direitos humanos de LGBTQI+ ${ }^{4}$. Por fim, podemos destacar, em 2004, a criação da Secretaria de Educação Continuada, Alfabetização e Diversidade (SECAD), instaurada para assegurar a ampliação do acesso à educação e a redução das desigualdades educacionais (CATRINCK; MAGALHÃES; CARDOSO, 2020). Vale destacar que, anteriormente, referimo-nos a uma ilusória democracia quanto aos estudos de gênero pelo fato de haver certa distância entre a promulgação de uma lei e seus efeitos pragmáticos no corpo social, principalmente se pensarmos no campo da educação, espaço em que os saberes científicos, culturais e a mão do Estado se misturam, ao longo dos séculos, ditando visões legitimadas como circulantes ou excludentes ao espaço educacional.

Assim, tais avanços legislativos não se fixaram significativamente no interior da escola, tampouco permaneceram como pauta oficial do Estado, posicionando-se muito mais como política transitória de governo do que como política pública de Estado. Logo, como discute Freire (1981, p. 69), o que se presencia, ao longo da história, é que o sistema educacional brasileiro assegurou a manutenção de uma escola "tradicional" em que se "[...] mata o poder criador não só dos educandos, mas também do educador", ao fomentar uma educação servil, autoritária e antidialógica que teme e subestima o valor da formação crítica, extirpando de suas bases temas considerados ruidosos. Exemplo disso foi verificado nos bastidores da elaboração do texto do Plano Nacional de Educação (BRASIL, 2014), que retirou termos como homofobia, identidade de gênero, lesbofobia, machismo, movimento feminista, orientação sexual, segregação, sexismo e transfobia da versão final do documento, em razão do conservadorismo de setores do Congresso Nacional, representado sobretudo pela bancada fundamentalista cristã.

É preciso não perder de vista que questões como homofobia e transfobia referem-se à sexualidade assim como referem-se também a preconceito, intolerância, discriminação e violência. Lembramos que gênero é "uma forma de se referir às origens exclusivamente sociais das identidades subjetivas de homens e de mulheres" (SCOOT, 1995, p. 75). Como afirmam Arán e Peixoto Jr. (2007, p. 134), "os atributos de gênero são performativos e não uma identidade préexistente", de maneira que uma pretensa "verdade sobre gênero" torna-se tão somente uma ficção reguladora. Como ficção reguladora, pode ser desnaturalizada, pois embora gênero seja "O mecanismo pelo qual as noções de masculino e feminino são produzidas e naturalizadas”, como explica Butler (2014, p. 253), pode também "muito bem ser o aparato através do qual esses termos podem ser desconstruídos e desnaturalizados". Logo, discursos heteronormativos na escola (ainda que não revelados como tais, mas encobertos por um falso discurso pró-família que reduz esta instituição a imagens que servem ao poder disciplinar) constitui o espaço escola não apenas como instância que exerce força centrípeta heteronormativa, mas sobretudo como um campo em que se deixa germinar o medo, a insegurança e a opressão, uma vez que a sexualidade, as identidades de gênero e suas dissidências não são portáveis - algo que se deixa do lado de fora da escola e se recolhe após a aula - sendo, ao contrário, algo corporificado na escola, que urge por proposições dialógicas, inclusivas e libertadoras.

Em complemento, é preciso levar em consideração que na atualidade, estamos cada vez mais envoltos por esses jogos políticos - cada vez mais acentuados - que retiram direitos fundamentais dos cidadãos. O Governo atual do presidente Jair Bolsonaro, apoiado e financiado por grupos políticos associados a discursos autoritário, conservador e elitista, não se intimida ao escancarar o seu desprezo por uma educação e sociedade democrática. São recorrentes, em seus pronunciamentos, falas que distorcem e desqualificam as pautas e o papel social de movimentos

\footnotetext{
${ }^{4}$ Neste trabalho, utilizamos a sigla LGBTQI+ para nos referirmos aos grupos não cis-heterossexuais. A primeira parte, LGB, refere-se à orientação sexual do sujeito, sendo: lésbica, gay e bissexual. A segunda parte, TQI, diz respeito à identidade de gênero: transexuais/travesti/transgênero, queer e intersexuais. O símbolo + representa as demais possibilidades de identidades de gênero, como por exemplo os assexuais, os fluidos, entre outros.
}

Práxis Educativa, Ponta Grossa, v. 16, e2116640, p. 1-14, 2021

Disponível em: < https://www.revistas2.uepg.br/index.php/praxiseducativa> 
Por uma educação freireana que atue contra a desigualdade de gênero no Brasil contemporâneo

pró-diversidade, que são intrínsecos às pautas democráticas (como os movimentos feminista, negro, surdo, indígena e LGBTQI+) e que se mostram tão importantes para a manutenção e fortalecimento da democracia, pois como ensina Freire (1996, p. 37), "a prática preconceituosa de raça, de classe, de gênero ofende a substantividade do ser humano e nega radicalmente a democracia".

Voltemos aos casos do movimento Escola sem Partido e às falas da Ministra Damares Alves para compreender a atuação das forças antidemocráticas em nosso país. Quando crises político-econômicas funcionam como substrato para grupos neofascista e reacionários crescerem à sombra do poder público, vemos sinais claros de que as trincas e fissuras do nosso regime democrático eram maiores do que se supunha. Este cenário legitima a repreensão, diminuição e silenciamento de minorias, além do controle e interdição sobre os discursos, indicando não apenas o que não se deve dizer, mas também aquilo que se deve dizer/fazer em cada conjuntura.

É justamente o que faz o citado movimento, que considera professores como um “"exército de militantes' que se vale da liberdade de cátedra e da 'cortina de segredo das salas de aula' para impor algo indesejado aos alunos", constrangendo-os com uma visão de mundo específica ao grupo (CATRINCK; MAGALHÃES; CARDOSO, 2020, p. 197). Nesse mosaico de controle, compete à Ministra Damares Alves, dessa vez, apontar o que pode ser dito/feito: como em vídeo que circulou após a sua posse, no qual a ministra brada, em meio a aplausos e gritos: "menino veste azul e menina veste rosa. Atenção, atenção: é uma nova era no Brasil"; justificando posteriormente ao Jornal Estado de São Paulo ter produzido "uma metáfora contra a ideologia de gênero, mas que meninos e meninas podem vestir azul, rosa, colorido, enfim, da forma que se sentirem melhor", exercendo uma força centrípeta nos discursos considerados desejáveis às crianças brasileiras.

Episódios como esse indicam a real possibilidade da perspectiva ideológica do governo influenciar diretamente a educação brasileira - através de políticas públicas e de currículos específicos - de modo a tolher ou reduzir a criticidade dos sujeitos, diminuindo o seu potencial reflexivo e, por consequência, sua capacidade de emancipação social.

Essa perspectiva nos provoca a refletir de que maneira a sociedade irá romper com os tabus de gênero e sexualidade que ocasionam uma série de pré-conceitos, já que a educação, que se configura com um dos principais meios de transformação, pode limitar-se a atender às ideologias do capital, deixando os indivíduos à mera disposição desse sistema. Um dos modos possíveis de enfrentamento, sem dúvida, se dá no front da sala de aula, onde cada professor (ainda) pode exercer a sua autonomia crítica.

E enquanto discussões que fomentem a igualdade de gênero e o respeito à diversidade sexual não se tornam parte integrante do currículo, muitos professores se questionam sobre como adentrar neste terreno espinhoso que hoje parece dominado por grupos que ameaçam, oprimem e até tentam criminalizar a profissão do professor. De nosso ponto de vista, professores de português (mas não apenas eles) ocupam uma posição privilegiada para resgatar e levar distintas vozes sociais para a sala de aula, com o intuito de examiná-las com os seus alunos. Não se trata, portanto, de aula sobre $\mathrm{x}$ ou y, mas da análise de discursos que atravessam a sociedade e cujos sentidos precisam ser desvendados criticamente pelo leitor proficiente.

Filiada a essa perspectiva, Felicíssimo (2020, p. 53) argumenta a favor da entrada da temática na escola e lembra que a desigualdade de gênero é responsável por inúmeros problemas sociais,

\footnotetext{
5 Vídeo disponível no link: https://exame.com/brasil/menino-veste-azul-e-menina-veste-rosa-diz-damares-emvideo/ , Acesso em: 06 mar. 2020, e matéria completa no link: https://brasil.estadao.com.br/noticias/geral,meninoveste-azul-e-menina-veste-rosa-diz-damares-alves,70002665826. Acesso em: 06 mar. 2020.
}

Práxis Educativa, Ponta Grossa, v. 16, e2116640, p. 1-14, 2021

Disponível em: < https://www.revistas2.uepg.br/index.php/praxiseducativa> 
como a diferença a menor dos salários recebidos pelas mulheres (ainda que desempenhando as mesma funções) e a menor possibilidade de participação delas na vida política, além das mulheres serem "as maiores vítimas de violência doméstica; de assédio no trabalho e de violência sexual"; sendo ainda as "que mais morrem em decorrência da violência empreendida por parceiros ou parentes homens", o que torna não apenas pertinente, mas urgente desconstruir estereótipos de gênero na Educação Básica, como sugere a autora por meio do estudo, por exemplo, de textos que circulam socialmente, como a charge a seguir:

Figura 1 - Charge sobre a representação da mulher

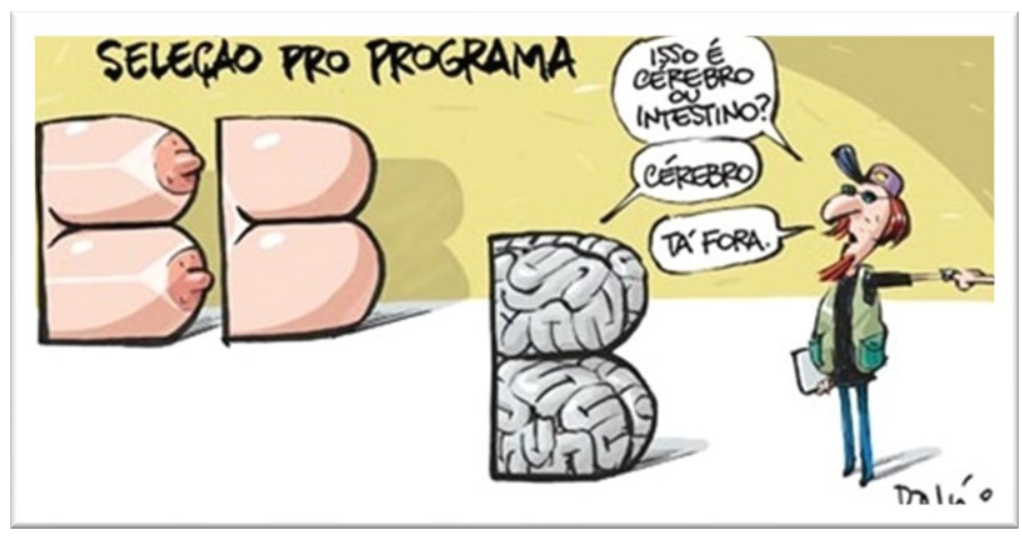

Fonte: http://imguol.com/2013/01/09/03-bbb-charge-1357746003809_500x250.jpg

Em relação à charge acima (fig. 1), Felicíssimo (2020) sugere que o seguinte percurso seja desenvolvido com os estudantes dos últimos anos do Ensino Fundamental. Inicialmente, em relação ao plano de expressão, é possível: i) identificar o gênero textual charge como uma primeira chave de leitura, por indicar um propósito comunicativo crítico e cômico comum ao gênero; ii) perceber que a figura feminina está representada metonimicamente por seios, nádegas e cérebro, o que conduz o leitor ao campo semântico do corpo; iii) perceber a dicotomia corpo $x$ mente indicada pela dúvida quanto a certa imagem rugosa, que seria descartada se fosse cérebro (mente), mas desejada se fosse intestino (corpo), construindo uma imagem de receptividade ao corpo feminino, mas não à sua mente. Em seguida, em relação ao plano de conteúdo, é possível ainda questionar aos alunos sobre os (inter)discursos que atravessam o texto em questão, perguntando: i) caso os elementos da figura feminina fossem substituídos por elementos de uma figura masculina, os mesmos sentidos seriam produzidos? ii) Por que nós, sujeito leitores sócio-historicamente condicionados, "reconhecemos a mulher naquele lugar (o do corpo erotizado), mas não o homem"? [...] "Por que somos levados a interpretar assim? O que autoriza essa interpretação? O que isso diz das relações estabelecidas entre os gêneros?” (FELICÍSSIMO, 2020, p. 57).

A charge sob análise indica um esforço social (no caso, o de um programa) para manter a mulher num espaço e lugar construído historicamente para ela. A partir daí, a discussão pode ser enriquecida com inúmeros fatos históricos, sociais e religiosos, que busca(ra)m construir limites para a mulher ao longo do tempo, em contraposição a inúmeros acontecimentos, conquistas e direitos contemporâneos, que têm diluído fronteiras e deslocado a mulher para todo e qualquer espaço social que queira ocupar.

Ao promover discussões como essa, estamos considerando a formação de indivíduos libertos e emancipados que buscam a superação da consciência ingênua. Nesse sentido, Freire (1981, p.39) afirma que o alcance à consciência crítica só é possível através de um "processo educativo de conscientização". Espera-se, portanto, que uma educação libertadora e crítica seja capaz de possibilitar um cenário no qual é possível discutir as perspectivas de gênero de modo 
reflexivo, dialético e não normatizador, de modo a não provocar opressão ou desumanização dos sujeitos. Para tanto, é fundamental que os educadores se comprometam com as classes populares, marginalizadas e oprimidas, no intuito de oferecer uma educação humanizada, crítica e libertadora para democracia.

Neste ponto do texto, acreditamos ter criado condições para responder à questão colocada no início deste estudo: que papel discussões sobre gênero desempenham na escola e na construção de uma sociedade mais justa e equânime? Entre inúmeras possibilidades, destacamos o imprescindível papel de desconstruir estereotipias, revisitar pré-construídos, fomentar o respeito mútuo, dirimir preconceitos e desenvolver uma consciência crítica coletiva capaz de levar os estudantes a olharem para si e para o outro como partes integrantes de um mesmo corpo social, orientando as novas gerações para o ideal da igualdade dentro da diversidade.

\section{Considerações finais}

Este estudo demonstrou que os pressupostos de Paulo Freire fornecem os subsídios necessários para pautar as perspectivas de gênero no cenário educacional brasileiro. Se almejamos fortalecer a frágil democracia brasileira, precisamos fazê-lo sobretudo por meio da escola, formando para a cidadania, o diálogo, o respeito e para o desenvolvimento de uma consciência crítica coletiva.

Sob essa égide, torna-se de grande valia teorizar e praticar a pedagogia proposta por Freire, a começar por nós, educadores, em ato de resistência à perpetuação de valores das classes dominantes que se opõem aos direitos das classes dominadas. Trata-se mesmo de uma luta diária pela humanização, pela não alienação dos sujeitos e pela promoção do diálogo crítico para que possamos viver em uma sociedade democrática, através de uma educação também democrática.

Por fim, esperamos que cada professor em cada ponto do país se sinta fortalecido e empoderado pelo legado original e nacional deixado pela obra de Paulo Freire quando se vir diante de temáticas sobre as quais pesem a força da interdição: somos muitos e nos apoiamos nos ombros de um gigante.

\section{Referências}

ABUD, K. Currículos de história e políticas públicas: os programas de história do Brasil na escola secundária. In: BITTENCOURT, C. O saber histórico na sala de aula. 9.ed. São Paulo: Contexto, 1998. p. 28-41.

ARÁN, M.; PEIXOTO JÚNIOR, C. A. Subversões do desejo: sobre gênero e subjetividade em Judith Butler. Cadernos Pagu, Campinas, n. 28, p. 129-147, 2007. DOI: https://doi.org/10.1590/s0104-83332007000100007

BUTLER, J. Regulações de gênero. Cadernos Pagu, Campinas, n. 42, p. 249-274, 2014. DOI: https://doi.org/10.1590/0104-8333201400420249

BRASIL. Presidência da República. Casa Civil. Decreto n $^{\circ}$ 1.904, de 13 de maio de 1996. Institui o Programa Nacional de Direitos Humanos - PNDH. Brasília, DF, 1996. Disponível em: http://www. planalto.gov.br/ccivil_03/decreto/D1904.htm. Acesso em: 06 jul. 2020. 
BRASIL. Ministério da Educação. Secretaria de Educação Fundamental. Parâmetros curriculares nacionais: ensino fundamental. Brasília, DF, 1997. Disponível em: http://portal.mec.gov.br. Acesso em: 06 jul. 2020.

BRASIL. Presidência da República. Casa Civil. Decreto no 3.952, de 04 de outubro de 2001. Dispõe sobre o Conselho Nacional de Combate à Discriminação - CNCD. Brasília, DF, 2001b. Disponível em: https://www.planalto.gov.br/ccivil_03/decreto/2001/d3952.htm. Acesso em: 06 jul. 2020.

BRASIL. Ministério da Saúde. Programa Brasil sem Homofobia: programa de combate à violência e à discriminação contra GLBT e de promoção da cidadania homossexual. Brasília, DF: Ministério da Saúde/Conselho Nacional de Combate à Discriminação, 2004. Disponível em: http://bvsms.saude.gov.br/bvs/publicacoes/brasil_sem_homofobia.pdf. Acesso em: 06 jul. 2020.

CATRINCK, I. M. O.; MAGALHÃES, S. A. B.; CARDOSO, Z. S. Políticas Públicas Educacionais de Gênero e Diversidade Sexual: avanços e retrocessos. Educação e Contemporaneidade, Salvador, v. 29, n. 58, p. 87-200, abr./jun., 2020. DOI: https://doi.org/10.21879/faeeba23580194.2020.v29.n58.p187-200

FONSECA, S. C. Paulo Freire e Anísio Teixeira: convergências e divergências (1959-1969). Jundiaí: Paco Editorial, 2011.

FRANCO, M. A. do R. S. Da necessidade/atualidade da pedagogia crítica: contributos de Paulo Freire. Revista Reflexão e Ação, Santa Cruz do Sul, v. 25, n. 2, p. 154-170, maio/ago. 2017. DOI: https://doi.org/10.17058/rea.v25i2.8891

FREIRE, P. Educação e mudança. Rio de Janeiro: Paz e Terra, 1981.

FREIRE, P. Pedagogia da autonomia. 6. ed. Rio de Janeiro: Paz e Terra, 1996.

FREIRE, P. Pedagogia da esperança. 7. ed. Rio de Janeiro: Paz e Terra, 2000.

FREIRE, P. Educação como prática de liberdade. E-book Kindle. São Paulo: Paz e Terra, 2014.

FREIRE, P. Conscientização. Trad. Tiago José Risi Leme. São Paulo: Cortez, 2016.

FELICÍSSIMO, M. A análise do discurso como estratégia para o ensino de leitura. In: RIBEIRO, M. C. M. de A.; LIMA, M. da P. B. Ação reflexiva no ensino de português. Montes Claros: Editora Unimontes, 2020. p. 52-71.

GRAMSCI, A. Os intelectuais e a organização da cultura. Rio de Janeiro: Civilização Brasileira, 2005.

HADDAD, S. O educador - um perfil de Paulo Freire. E-book Kindle. São Paulo: Todavia, 2019.

NUNES, C. Paulo Freire e a retomada orgânica da luta social e política para conquistar o direito à educação na perspectiva da legitimação jurídica e pedagógica da educação como direito. Revista de Ciências da Educação, Americana, n. 44, p. 67-108, out. 2019. DOI: https://doi.org/10.19091/reced.vi0.858

SCOTT, J. Gênero: uma categoria útil de análise histórica. Educação \& realidade, Porto Alegre, v. 20, n. 2, 1995. 
SILVA, A. N. da. As contribuições do pensamento de Paulo Freire para os estudos sobre as masculinidades. Práxis Educativa, Ponta Grossa, v. 16, e2115294, p. 1-16, 2021. DOI: https://doi.org/10.5212/praxeduc.v.15.15294.033

Recebido em 11/08/2020

Versão corrigida recebida em 24/03/2021

Aceito em 25/03/2021

Publicado online em 29/03/2021 